\title{
Communicating science in the time of Coronavirus: What we have learned
}

\author{
Greta Barbieri, ${ }^{1-2}$ Erika Poggiali, ${ }^{3}$ Francesco Salinaro, ${ }^{4}$ Veronica Salvatore ${ }^{5}$ \\ ${ }^{1}$ Department of Surgical, Medical, Molecular and Critical Area Pathology, University of Pisa; ${ }^{2}$ Emergency \\ Medicine Department, Pisa University Hospital, Pisa; 3Emergency Department, Ospedale Guglielmo da \\ Saliceto, Piacenza; ${ }^{4}$ Emergency Medicine Unit, IRCCS Polyclinic San Matteo Foundation, Department of \\ Internal Medicine, University of Pavia, Pavia; ${ }^{5}$ Emergency Department, Medicina d'Urgenza e Pronto \\ Soccorso, IRCCS Azienda Ospedaliero-Universitaria di Bologna, Italy
}

One of the greatest and most famous Greek philosophers, Socrates, believed that "here is only one good, knowledge, and one evil: ignorance", but nowadays we can tentatively add that knowledge without sharing is like sterile ground. Today, social media play a central role not only in connecting people worldwide, but overall to access news and information, and for decision making.

The recent COVID-19 pandemic represented a critical moment in our human and professional experience. We faced an urgent need to quickly share information in a field that had not yet been explored. Each of us has experienced a feeling of disorientation, lack of adequate medical tools to contrast an unknown disease, in addition to loneliness and isolation that circumstances have imposed, above all on health professionals. In this context, technological tools previously under-used in our field, including social media, have allowed us to directly and immediately share the information available.

"In the next influenza pandemic, be it now or in the future, be the virus mild or virulent, the single most important weapon against the disease will be a vaccine. The second most important will be communication". This evocative sentence was written in May 2009 by John M Barry ${ }^{1}$ in the early phases of what would soon become the $2009 \mathrm{H} 1 \mathrm{~N} 1$ pandemic. In his essay, Barry summarized the mishandling of the deadly 1918 Spanish influenza, highlighting the importance of precise, effective, and honest information at the onset of health crises. ${ }^{2}$

Despite the mistakes made and the parallel risk of a wide misinformation, COVID-19 also taught us that the diffusion of data is useful only after proof according to a solid scientific method and

Correspondence: Greta Barbieri, Department of Surgical, Medical, Molecular and Critical Area Pathology, University of Pisa, Emergency Medicine Department, Pisa University Hospital, Via Paradisa 2, Pisa, Italy.

E-mail: greta.barbieri@phd.unipi.it

Key words: COVID-19; communication; editorial.

Received for publication: 16 September 2021

Accepted for publication: 16 September 2021.

This work is licensed under a Creative Commons Attribution 4.0 License (by-nc 4.0).

${ }^{\circ}$ Copyright: the Author(s), 2021

Licensee PAGEPress, Italy

Emergency Care Journal 2021; 17:10139

doi:10.4081/ecj.2021.10139 not based on experience alone. These reflections must renew our sense of responsibility as physicians and editors, in supporting a rigorous approach of sources and methodology.

We strongly believe that social networks could be excellent tools in the scientific field to communicate quickly and shortly, to create dialogue and discussions on a specific topic, just taking care of the authority of the source. For this reason, we have created two social media accounts on Facebook and Instagram (@emergencycarejournal) as two virtual easily accessible places, where researchers and clinicians can have the great opportunities to access and share articles and information. We want to create, improve, share and spread knowledge. It's a new adventure for our journal and a big communications landscape for all of us!

In this issue, we are very proud to present an obituary in memory of Dr. Gino Strada, a doctor who strongly believed that "the right to receive adequate medical care is a universal right", universally known as the founder of EMERGENCY. The memorial has been written by an EMERGENCY's physician who had the privilege to work with him and who is continuing to carry out his vision of medicine here and abroad, Dr. Giorgio Monti. ${ }^{3}$

This latest issue also features the original paper by Aschieri et al. about low molecular weight heparin (LMWH) dosage in COVID-19 patients. Here they suggest that LMWH at therapeutic doses could exert a beneficial effect on the clinical course of COVID-19 thanks to its anticoagulant, anti-inflammatory and in vitro antiviral properties. ${ }^{4}$ The other original paper that adds knowledge to scientific community regarding COVID-19 therapy is the one by Vergnano et al., who argue that corticosteroids in selected COVID-19 patients may have a relevant impact on outcome. $^{5}$

As we know, COVID-19 affected not only the body but also the mind. Beghi et al. demonstrated an increase in number of admissions for psychiatric evaluations after the lockdown, compared to those of the previous year, underlining the negative psychological effects of quarantine and the need of specific support. ${ }^{6}$

COVID-19 pandemic also notably increased the use of HighFlow Nasal Cannula (HFNC) for respiratory support, in alternative to traditional low-flow nasal cannulas or to prevent continuous positive airways pressure and mechanical ventilation. Pierantoni et $a l$. present a case report of occult pneumomediastinum, a rare but life-threatening complication of HFNC that occurred in a 3 months-old infant admitted for acute bronchiolitis. ${ }^{7}$

Clinical deterioration, especially in case of rapid onset, should be promptly detected in Emergency Department (ED); so Reed et al. illustrated a new continuous device that detected worsening on average one hour earlier than manual vital signs. ${ }^{8}$

Lastly, two Turkish original papers deserve attention: one about concomitant administration of multiple drugs in intravenous fluids and the possible increase of allergic reactions risk ${ }^{9}$ and the other about the satisfaction evaluation levels of expatriate patients 
presenting to ED. ${ }^{10}$ An incredibly wide spectrum of clinical situations accesses every day in Emergency Department and clinicians should keep all of these aspects in mind. Rare (and thus often forgotten) but potentially life-threatening diseases are highlighted in the other case reports included in this issue: emphysematous pyelonephritis, ${ }^{11}$ Kounis syndrome, ${ }^{12}$ and rupture of a parathyroid adenoma. ${ }^{13}$

We hope that you will be as satisfied as we have been while reading this issue, and that you will continue to share knowledge about that challenging and ever surprising field of interest that is Emergency Medicine.

Dear readers, welcome in our new "social community" and stay connected with us!

\section{References}

1. Barry JM. Pandemics: avoiding the mistakes of 1918. Nature 2009;459:324-5.

2. Gozzi N, Tizzani M, Starnini M, et al. Collective response to media coverage of the COVID-19 Pandemic on Reddit and Wikipedia: Mixed-methods analysis. J Med Internet Res 2020;2:e21597.

3. Monti G. Gino Strada (1948-2021). Emerg Care J 2021;17:10135.

4. Aschieri D, Stabile M, Maestro C, et al. Potential benefits of anticoagulant doses of low molecular weight heparin in COVID-19: An observational retrospective study. Emerg Care J 2021;17:9795.
5. Vergnano B, Calcinati S, Signori D, et al. Steroids in severe COVID-19 patients: A retrospective analysis on the first pandemics in Lombardy. Emerg Care J 2021;17:9888.

6. Beghi M, Brandolini R, Biondi L, et al. Effects after the lockdown on emergency room admissions for psychiatric evaluation: An observational study from the province of ForlìCesena, Italy. Emerg Care J 2021;17:9827.

7. Pierantoni L, Dondi A, Biagi C, et al. Subcutaneous emphysema of the neck as a complication of high flow therapy in children: A case report. Emerg Care J 2021;17:9615.

8. Reed MJ, O'Brian R, Black PL, et al. Physiological deterioration in the Emergency Department: The SNAP40-ED study. Emerg Care J 2021;17:9711.

9. Çakmak ME, Kaya SB, Bostan OC, et al. Allergic reactions due to concomitant administration of multiple drugs in intravenous fluid in emergency departments in Turkey. Emerg Care J 2021;17:9848.

10. Ersoy S, Konar NM, Çalışkan HM, et al. Evaluation of satisfaction levels of expatriate patients presenting to emergency department. Emerg Care J 2021;17:9812.

11. Poggiali E, Tansini F, Christodoulakis K, et al. A case of hematuria and vomiting in the emergency room: Never forget the emphysematous pyelonephritis. Emerg Care J 2021;17:9847.

12. Fiore G, Gaspardone C, Di Maio S, et al. Kounis syndrome after almonds ingestion: From the diagnostic approach to new therapeutic options. Emerg Care J 2021;17:9806.

13. Porta L, Ghezzi R, Cadonici AC, et al. An unusual case of neck hematoma and hypercalcemia. Emerg Care J 2021;17:9548. 